\title{
Légitime Défense: surrealismo negro, anticolonialismo y la producción de la identidad martinicana $^{1}$
}

\section{Légitime Défense: Black Surrealism, Anticolonialism and the Production of Martinican Identity}

\author{
Magdalena Sophia Toledo \\ Instituto de Estudios Avanzados, Universidad de Santiago. Santiago, Chile. \\ magdalena.sophia.toledo@gmail.com
}

\section{Resumen}

Este artículo propone un análisis de la revista Légitime Défense, creada en 1932 por un grupo de estudiantes de Martinica en París. El medio surge de la afectación que este grupo manifiesta hacia los debates surrealistas y marxistas, en tanto potencializadores de la crítica anticolonial y moduladores de nuevas sensibilidades estéticas y políticas. Creada en un contexto de "internacionalismo negro" y de debate in loco con estas vanguardias europeas, Légitime Défense inaugura a la vez el surrealismo negro y antillano, al producir un discurso anticolonialista a partir del caso martinicano que está en el origen de los primeros debates identitarios en esta isla caribeña.

Palabras clave: surrealismo, anticolonialismo, marxismo, Légitime Défense, identidad martinicana

\section{Abstract}

This article presents an analysis of the review Légitime Défense, created in 1932 by a group of Martinican students in Paris. It stems from their affection by the surrealists and Marxists debates, as factors of maximization of anticolonial critics and modulators of new esthetic and political sensibilities. Created in a context of "black internationalism" and on-site debates with these European vanguards, Légitime Défense inaugurates at once black and Antillean surrealism by producing an anticolonialist discourse from the Martinican case, which is in the origins of the first debates of identity in this Caribbean island.

Palabras clave: Surrealism, Anticolonialism, Marxism, Légitime Défense, Martinican identity.

1 Agradezco al Proyecto Postdoc_dicyt, Código 031694PC postdoc, Vicerrectoría de Investigación, Desarrollo e Innovación. Universidad de Santiago de Chile, USACH. 
Creada en 1932 por un grupo de estudiantes martinicanos residentes en París, entre quienes se contaban Étienne Léro, Thélus Léro, René Ménil, Jules-Marcel Monnerot, Michel Pilotin, Maurice-Sabas Quitman, Auguste Thésée y Pierre Yoyotte, y marcada por un discurso anticolonialista fuertemente influenciado por los debates instaurados por surrealistas y marxistas, Légitime Défense es considerada el marco inaugural del surrealismo antillano (Leiris 101) y del surrealismo negro (Rosemont y Kelley). Con un único número y calificada como subversiva por las autoridades coloniales francesas, la revista fue prohibida de circular y sus integrantes perdieron sus becas de estudios. Légitime Défense marca también el surgimiento de una vanguardia literaria responsable por los primeros debates sobre la identidad martinicana, anclados en la crítica anticolonial.

Este artículo pretende analizar de qué modo los debates surrealistas, en conjunto con los marxistas -alianza que se estableció al principio de este movimiento, siguiendo la tendencia observada en otras vanguardias artísticas del siglo xx (Hobsbawm 190)-, modularon sensibilidades estéticas y políticas que están en la base de la formación de esta vanguardia martinicana, así como sus repercusiones en los discursos anticolonialistas e identitarios en Martinica.

Particularmente en el caso martinicano, el movimiento surrealista produjo efectos en la modulación de una sensibilidad estética y de un discurso político, al revelarse como un agenciamiento presente en la formación de una primera crítica literaria al colonialismo europeo que, más tarde, tendría eco en el movimiento de la negritud y en el discurso anticolonialista de Aimé Césaire (Discours sur le colonialisme; Le discours sur la négritude). Además, se constituyó como uno de los propulsores del proyecto de producción de una identidad martinicana entendida como parte de un contexto negro, caribeño y latinoamericano más amplio.

Como señala el especialista en literatura caribeña J. Michael Dash, fue "sin duda en el Caribe y en América del Sur que el surrealismo produjo un debate largo y sólido sobre la cuestión de la relación entre Europa y sus otros coloniales" (84). ${ }^{1}$ Sin embargo, el mismo autor indica que la producción surrealista resultante de la interacción entre una vanguardia literaria francesa y escritores caribeños no fue suficientemente analizada, a lo que podemos agregar una mirada hacia estas creaciones en tanto un apéndice o aspecto secundario del movimiento europeo. Lo mismo puede ser observado en relación con otros surrealismos periféricos y, entre estos, particularmente en la producción de los surrealistas negros (Rosemont y Kelley). Para explicar este silenciamiento de importantes efectos y trayectorias del movimiento, los autores apuntan a la "invisibilidad" de los surrealistas negros del Caribe, Latinoamérica, África y Estados Unidos en distintas antologías y análisis académicos, lo que contribuiría a la producción de la imagen de un "movimiento enteramente blanco, así como otras escuelas artísticas de origen europeo" (Rosemont y Kelley 1).

1 Todos los pasajes de obras en idioma distinto al español citadas en el artículo son traducidos por la autora. 
Por otro lado, el grupo de Légitime Défense presentaba algunas especificidades si se lo compara con otras "apropiaciones periféricas" del movimiento surrealista. La primera de ellas es la interlocución in loco con este movimiento ya en sus principios, aliada a la situación de dominación colonial aún vigente en Martinica en el momento de su surgimiento. ${ }^{2}$ Esta doble posición -marginal políticamente, pero a la vez central en relación con los debates surrealistas- le confiere una mirada particular al interior de los debates de vanguardia producidos en Europa, y además está en la raíz del pionerismo de su producción.

De este modo, la singularidad del caso martinicano que marca esta producción surrealista revela una afectación, por parte de los habitantes de las colonias, de conceptos y sensibilidades formadas en la metrópolis en función de una crítica al propio colonialismo. Si esta crítica ya estaba presente en el movimiento surrealista desde su surgimiento, ahora se trataba de los sujetos bajo dominio colonial hablando por sí mismos, instrumentalizando conceptos producidos en y por Occidente. Contribuyó a esto el ambiente de "internacionalismo negro" presente en París en el periodo de entreguerras vivido por sus creadores (Bouvier, Bonfiglio, Davis, Fonkoua, Kesteloot, Kesteloot y Kotchy, Toumson y Henry-Valmore, Tomich), a lo que se suma una serie única de encuentros entre escritores caribeños francófonos y surrealistas franceses en la capital francesa entre los años de 1932 y 1936, encuentros que marcan un momento de extrema importancia en la lucha anticolonial en el mundo francófono (Richardson, Refusal of the Shadow). Así, más allá de ser simplemente influenciada por los debates europeos, Légitime Défense inaugura una producción surrealista con características propias, en la cual la crítica al colonialismo y a la burguesía martinicana, además de los debates en torno a la cuestión identitaria, constituyen ejes centrales de reflexión.

Autores como Cole señalan la "apropiación [por parte de los autores de la revista] de la retórica comunista y surrealista con el propósito de iniciar una consciencia literaria y política caribeñas" (15). La autora destaca igualmente el uso del género del manifiesto por los autores de la revista, ejercido tanto por los comunistas como por los surrealistas, ${ }^{3}$ como la apropiación "de un modelo europeo de autoridad textual para definir una agenda caribeña única” (15). Sin embargo, yendo más allá de la idea de apropiación de una retórica o de un género textual, propongo que estos autores fueron afectados por los debates surrealistas y marxistas en un sentido más amplio, que abarca la formación de nuevas sensibilidades moduladas por estos discursos. En este punto, propongo una articulación entre la idea de afectación y la noción de

2 Como señalan Rosemont y Kelley, la mayor parte del grupo de Légitime Défense participaba activamente de las reuniones del grupo surrealista, donde tenían lugar discusiones sobre arte, política y anticolonialismo. Además, el nombre de la revista hace mención al ensayo homónimo de André Breton de 1926, publicado en la revista $L a$ révolution surrealiste, lo que indica la proximidad entre los autores martinicanos y los integrantes del movimiento europeo desde su surgimiento, así como su filiación explícita.

3 Manifiesto Comunista (1848), Manifiesto Surrealista (1924), Segundo Manifiesto del Surrealismo (1930). 
"sensibilidades etnográficas" de Stocking, de modo tal que las nuevas sensibilidades antillanas serían el resultado de este proceso de afectación.

Stocking analiza el proceso de formación de una "sensibilidad etnográfica" en los años veinte en Estados Unidos, la cual condujo a un creciente interés por el conocimiento de "otros culturales", compartido tanto por los jóvenes antropólogos -que veían en el trabajo de campo un punto central no solamente de constitución disciplinaria, sino de encuentro con alteridades culturales cada vez más valoradas- como por vanguardias artísticas e intelectuales. En su proceso de vivencia y creación de una contracultura basada en una idea de antítesis a la civilización moderna, buscaban fundamento en un primitivismo idealizado, muchas veces asociado a comunidades rurales, indígenas o populares de las periferias urbanas, que vinculaban a una idea de "cultura genuina" en contraposición a un estilo de vida moderno, representado por ideales de progreso. Este conjunto de ambientes, ideas y sensibilidades compartidas configuró una experiencia común entre los jóvenes antropólogos y las vanguardias artísticas e intelectuales en Estados Unidos, en la cual se entrecruzan los modernismos culturales y una antropología en formación.

Un proceso similar fue analizado por Clifford en su examen de la aproximación entre etnografía y surrealismo en Francia en el periodo de entreguerras, en el cual una actitud surrealista permeaba el mundo de las ciencias humanas, que mantenía un contacto íntimo con el mundo de las artes y la literatura (Clifford 18), al mismo tiempo que la etnología informaba sobre "mundos exóticos" y otras posibilidades de existencia más allá de los modos de vida occidentales. De esta forma, antropólogos y surrealistas compartían una "actitud etnográfica surrealista”, en la cual, "al contrario del exoticismo del siglo xIx, [...] los otros aparecían ahora como serias alternativas de humanidad" (120).

En el caso específico de Légitime Défense, además de la producción de una "agenda caribeña única" (Cole) a partir de la apropiación de géneros literarios o discursivos, destaco lo que considero como el surgimiento de sensibilidades surrealistas que, entre otras, comprendían el arte como un vehículo de transformaciones existenciales y políticas, "afectando" la estrecha vinculación entre arte y política en la literatura martinicana más allá del breve periodo de existencia de la revista, como atestiguan los desdoblamientos de estos debates en la formulación de un primer discurso identitario en Martinica. En este sentido, la revista "refuerza y expande el proyecto revolucionario del surrealismo", tal como señalan Rosemont y Kelley.

De este modo, en el análisis de Légitime Défense, utilizaré la idea de afectación con el propósito de ampliar la noción de influencia o de apropiación de los intelectuales martinicanos de discursos producidos en la metrópoli, y abarcar, además, la formación de sensibilidades (estéticas, existenciales y políticas) en torno a la cuestión identitaria, sensibilidades que modularon no solamente las manifestaciones de vanguardia en Martinica, sino sus movimientos literarios posteriores. La formación de nuevas sensibilidades antillanas sería el resultado, entonces, de las "afectaciones" generadas por estos discursos. 
Para ello, en un primer momento discutiré algunas características generales del movimiento surrealista en sus primeros años, que fueron fundamentales para la crítica anticolonial de Légitime Défense, así como para sus debates sobre la cuestión identitaria. Además, analizaré el contexto en el cual se dio la alianza entre surrealistas y comunistas en Francia poco antes del surgimiento de la revista, con lo que pretendo presentar algunos elementos que contribuyan a la reflexión sobre sus filiaciones y especificidades en relación con estos dos marcos fundamentales.

\section{Los primeros años surrealistas: revolución existencial y la alianza con el PCF}

El surrealismo no se restringe a un movimiento estético de vanguardia europeo vinculado a los cuestionamientos de los valores occidentales emprendido por un grupo específico de artistas en el periodo de entreguerras. Tampoco la definición del movimiento solamente en términos estéticos daría cuenta de su alcance, puesto que, desde el principio, el movimiento buscó afirmarse, más allá de una forma de intervención poética, como un proyecto de revolución existencial. De esta manera, comprenderlo como "surrealismo histórico", en tanto "crítica social" que supera las reificaciones muchas veces establecidas en los estudios de historia del arte o estudios literarios (según Richardson, "An Encounter"), puede conducir a una mayor apreciación de los sentidos y efectos del movimiento. Como señala Richardson, "pese a ser claramente, y conscientemente, un desarrollo del Romanticismo, el surrealismo no puede ser entendido como un movimiento [solamente] artístico: él fue una actitud, una manera de vivir, mirar y relacionarse con el mundo" (Refusal of the Shadow 58).

En este sentido, la Déclaration du 27 janvier 1925, redactada por Antonin Artaud y firmada por los primeros integrantes del movimiento un año después del Primer Manifiesto Surrealista, puede ser tomada como una afirmación de este proyecto: "El surrealismo no es un medio de expresión nuevo o más simple, ni una metafísica de la poesía; es un medio de liberación total del espíritu y de todo lo que a ello se asemeja. Nosotros estamos totalmente decididos a hacer una Revolución". ${ }^{4}$

De este modo, desde el principio del movimiento, la forma poética es apuntada no como un fin en sí mismo, sino como un instrumento de una revolución existencial y política. Como declaran los signatarios de la Déclaration en su primer párrafo: "Nosotros no tenemos nada que ver con la literatura, pero somos bien capaces, si es necesario, de servirnos de ella como cualquiera”. Del mismo modo que la literatura podría ser un instrumento a través del cual se buscaba esta revolución existencial,

4 "Le surrealisme n’est pas un moyen d'expression nouveau ou plus facile, ni même une métaphysique de la poésie; Il est un moyen de libération totale de l'esprit et de tout ce qui lui ressemble. Nous sommes bien décidés à faire une Révolution." Fuente: https://www.benjamin-peret.org/le-surrealisme/230-declaration-du-27-janvier-1925.html 
artefactos producidos por los llamados pueblos "primitivos" o "no Occidentales" se transformaron igualmente en elementos que podrían ser utilizados como una vía de acceso a esta transformación, sobre todo por estar asociados a sensibilidades que escapaban al racionalismo occidental.

Aliado a ciertas concepciones de primitividad -y, muchas veces, asociado a esta- el concepto de inconsciente, tal como fue formulado por Freud, también fue apropiado y afectó a los artistas vinculados al movimiento surrealista, lo que se observa en sus experimentaciones estéticas y en su fascinación por los artefactos "no Occidentales". Estas creaciones, consideradas "no contaminadas" por el racionalismo occidental, fueron vinculadas a nociones de "primordialidad" u "originalidad" (De L'Estoile 43) y asociadas a una idea de mayor proximidad al inconsciente, relacionado, a su vez, a una idea positivada de primitividad.

Por otro lado, la idea de revolución existencial emprendida por los surrealistas franceses (abierta, por definición, a múltiples sentidos) también produjo desdoblamientos, e influyó en el establecimiento de posicionamientos más explícitamente políticos, sobre todo en el principio del movimiento, como atestigua la aproximación de los surrealistas al Partido Comunista Francés ya en 1925. Aun sin una adhesión integral de sus miembros al partido, hasta 1935 los comunistas se tornaron los principales aliados de los surrealistas en la crítica al colonialismo (Cole, Leclerq, Lewis, Reynaud-Paligot). En este sentido, la revista La Révolution Surréaliste (1924-1929) ya demostraba un interés por los debates marxistas, como afirmaba la disposición de los surrealistas en la formación de una alianza en torno a causas comunes, empezando por el anticolonialismo. Fueron actividades anticolonialistas realizadas por los surrealistas en 1925 (año en que Francia estaba en guerra con Marruecos) las que los pusieron en contacto por primera vez con los comunistas. En esta época los surrealistas no se afiliaron al Parti Communiste Français (PCF), pero formaron una coalición con procomunistas e intelectuales revolucionarios. Como resultado, escribieron (en conjunto con el grupo del periódico Clarté) el manifiesto La révolution d'abord et toujours!, contra la guerra de Marruecos, que marca el inicio del compromiso político directo de los surrealistas con la revolución social y la acción política (Lewis 7-8). Así, durante el año de 1925, en la revista La Révolution Surréaliste, textos como "Communisme et révolution" de Louis Aragon ( $\mathrm{n}^{\circ} 2$ ), "La suppression de l'esclavage" de Paul Eluard ( $n^{\circ} 3$ ) y "Léon Trotsky: Lénine" de André Breton ( $\left.n^{\circ} 4\right)$ dan cuenta de este proyecto.

Sin embargo, el año siguiente (1926) ya empiezan a revelarse tensiones e incomprensiones de parte del PCF en relación con la forma de adhesión de los surrealistas, sin filiación o compromiso irrestricto para con los cánones del partido. En principio, "los comunistas sospechaban de una organización que posicionaba su movimiento como una revolución [lo que era reforzado por el título de la revista] -pues consideraban la revolución proletaria como la única revolución verdadera-” (Lewis 7). Además, los surrealistas se posicionaban como un grupo autónomo, que deseaba mantener su autonomía respecto del partido, por lo que se negaban a desistir de sus actividades 
y a seguir la disciplina de aquel. Es en este contexto que, en 1926, Breton publica el texto "Légitime Défense" en La Révolution surréaliste n 8 . A modo de una "legítima defensa", Breton da cuenta justamente de estas tensiones y busca explicar el carácter de la adhesión surrealista al programa comunista: "adhesión en principio entusiasta aunque se trate de un programa mínimo" (30); asimismo, señala las reticencias de los comunistas a recibir esta adhesión no irrestricta, que se revelaban, según el autor, casi como una negación. En respuesta, Breton intentaba puntuar la falacia de la oposición entre "la realidad interior y el mundo de los hechos" (34), y reafirmaba el marco en el cual se circunscribía la adhesión surrealista al proyecto comunista:

En el ámbito de los hechos, de nuestra parte, ningún equivoco es posible: no hay nadie entre nosotros que no desee el paso del poder de manos de la burguesía a las del proletariado. Mientras tanto, no es menos necesario, según nosotros, que prosigan las experiencias de la vida interior, y esto, evidentemente, sin control exterior, incluso marxista (34-5).

Las tensiones no cesaron hasta 1930, con la creación de la revista Le Surréalisme au service de la révolution (1930-1933), que marca el compromiso del grupo surrealista (que ya contaba con muchos de sus integrantes, como Breton, afiliados al partido desde 1927) con las directrices de la Tercera Internacional, en un periodo caracterizado por el compromiso político abierto con las actividades anticolonialistas (Lewis 8).

Uno de los principales marcos de esta alianza fue su posicionamiento contrario a la Exposition coloniale de París de 1931. Esta exposición tuvo un gran impacto en la construcción del imaginario colonial en Francia, y se inserta en el contexto político general del periodo de entreguerras: tras la Primera Guerra, la confianza en la propia cultura francesa se vio impactada, lo que justificó la necesidad de reforzar el sentimiento de comunidad nacional en torno al Imperio Colonial Francés. Con el propósito de exaltar las "conquistas coloniales", así como de reforzar en la opinión pública la idea de "carácter civilizatorio" de estas misiones sobre las colonias, la exposición buscaba recrear una especie de "microcosmos" del Imperio Colonial Francés en su apogeo. A partir de la invitación a descubrir una "Gran Francia” y a tomar "le tour du monde en une journée”, la exposición, que tuvo más de ocho millones de asistentes, proyectaba la imagen de una Francia gloriosa, promotora del progreso en las colonias, el cual se sustentaba abiertamente en un presupuesto de superioridad de la civilización francesa.

Con pabellones dedicados a cada grupo de colonias francesas, los organizadores de la exposición ofrecían una visión al mismo tiempo idealizada del mundo colonial y exotizante de los no occidentales, lo que contribuía a la promoción de una euforia chovinista en relación con las conquistas coloniales. Además de su tono propagandístico, sus organizadores tenían una ambición didáctica de fondo: crear una gran narrativa nacional en torno al Imperio Colonial Francés.

Como parte de las acciones contrarias a la exposición, los surrealistas iniciaron una campaña para su boicot, lanzaron el manifiesto Ne visitez pas l'Exposition Co- 
loniale y se aliaron a la Liga Antimperialista vinculada al Partido Comunista en la organización de la contraexposición La Vérité sur les colonies. La misma, compuesta de fotografías, afiches, documentos, fétiches européens y objetos de arte no occidentales (estos últimos, debido a la influencia surrealista de Louis Aragon, responsable de la organización de la sala dedicada a la "presentación de los problemas culturales" del colonialismo), tuvo lugar en la Maison des Syndicats de París. La idea, como el propio nombre sugiere, era realizar una denuncia del colonialismo y deconstruir la visión idealizada de la empresa colonialista, así como del "mito de la misión civilizadora" francesa (Leclerq, Barthes), presentes en la Exposition coloniale. Pese a que convocó un número de visitantes significativamente menor que la Exposition coloniale (solamente cinco mil), la contraexposición se afirmó como una acción estética de confrontación directa al aparato colonial y su discurso civilizatorio hegemónico en una época en que la posición anticolonial era todavía "muy minoritaria" (Leclerq 318).

$\mathrm{Si}$, por un lado, la exposición puede ser vista como un ejemplo de la cooperación entre surrealistas y comunistas en la denuncia del colonialismo, por otro, se constituyó como una ocasión más en que se revelaron sus diferentes (y muchas veces irreconciliables) visiones del mismo (Blachère, Palermo). Los propios artefactos elegidos para la confrontación de la narrativa de exaltación del colonialismo presente en la Exposition Coloniale dan cuenta de estas distancias, como atestigua la tensión entre los responsables por la organización de la muestra: André Thirion, representando a la Liga Antimperialista del Partido Comunista, y el surrealista Louis Aragon. Si la sección a cargo del primero seguía el método didáctico defendido por el partido (Palermo), en la sección organizada por Aragon, Tanguy y Éluard vemos una articulación entre objetos de art primitif, fétiches européens y afiches de protesta que revela una lectura del colonialismo más próxima a los ideales surrealistas. Para estos últimos, la aproximación al "primitivo" -o, más bien, a ideales de "primitividad" vinculados a los pueblos no occidentales- era una forma de crítica existencial, filosófica y política a los valores occidentales, que todavía intentaban conciliar con la crítica marxista. Frente a las tensiones con los comunistas en torno a la presencia de objetos de "arte primitivo" en la exposición, recurrían a Marx y Engels, justificando que estos artefactos "eran dignos de interés como elementos dialécticos oponibles al arte 'fruto de la economía capitalista”" (cit. en Blachère 38).

Así, en las salas organizadas por los surrealistas observamos la estética de bricolajes e "inesperadas yuxtaposiciones" característica del surrealismo (Clifford 118). De este modo, artefactos provenientes de lugares y contextos coloniales diversos forman instalaciones en torno al tema de la dominación colonial, cuyo sentido -pese a ser portador de una crítica explícita a la política imperialista- debería ser completado por el espectador, lo que contrariaba las expectativas didácticas del arte político marxista del periodo. ${ }^{5}$

5 Como ejemplo, en una de las salas, un afiche con la sentencia parafraseada por Karl Marx, "Un pueblo que oprime a otros no puede ser libre" se expone en medio de objetos de arte africanos; medallas y condecoraciones militares de los ejércitos coloniales, haciendo mención a la "masacre colonial", son presentados junto a objetos que aluden a 
Por consiguiente, las propias fricciones provenientes de diferentes visiones del colonialismo y sobre todo de diversas acciones para su enfrentamiento, visibles en momentos como el de la exposición, dan cuenta de divergencias que se tornarán irreconciliables con el tiempo. Como señalan diversos autores, "de modo diverso a los comunistas, los surrealistas no adhirieron a la primacía de la revolución proletaria" (Lewis 9). En una visión más matizada del oprimido colonial, este "no se reduce al proletario" (Leclerq 318). De este modo:

Su rechazo del Occidente sobre el plano de la cultura, así como su fascinación por los mundos no-occidentales, que ellos engloban bajo la categoría del Primitivo, les invitan a considerar la alienación colonial más allá de la visión comunista. En este sentido, la representación poética, estética y casi romántica que ellos hacen de los no-Occidentales y, por consiguiente, de los colonizados es, del mismo modo que el modelo revolucionario comunista, el material de su anticolonialismo (Leclerq 318).

Así, el anticolonialismo de los surrealistas se inserta en un contexto de cuestionamiento más amplio de los valores occidentales, lo que está en la base de su afectación por las culturas y artefactos no occidentales (aunque sean originados por proyecciones e idealizaciones diversas). Como señala Lagrou, "Los surrealistas eran enfáticamente anticolonialistas, y parecen haber solidarizado antes con el oprimido por el colonialismo que con el oprimido más cercano, el proletariado” (221).

Richardson sugiere incluso un sentido de derivación de la adhesión surrealista a las ideas anticolonialistas, afirmando que "como una revuelta generalizada contra las propias fundaciones de la civilización occidental y su moralidad, el surrealismo se sintió inmediatamente atraído por las culturas no-occidentales, y temas relacionados al colonialismo rápidamente tuvieron efectos en las reflexiones surrealistas" (3). En este sentido, son representativas las experimentaciones estéticas sobre la base de conceptos, formas musicales, rituales y, sobre todo, objetos creados por los llamados "pueblos primitivos" que, además, eran vistos como medios de una revolución existencial, indisociable de la idea de revolución estética. De este modo,

Las simpatías con la revolución apuntaban antes a una revolución de mentalidad que a una revolución armada, y los surrealistas estaban tan interesados en transformarse a sí mismos como lo estaban en transformar el mundo. Las poblaciones colonizadas ultramarinas se ofrecían de este modo como aliadas naturales, en el sentido de que estas parecían poseer la solución existencial buscada por los surrealistas (Lagrou 221-222 [énfasis en el original]).

la imagen idealizada del bon nègre de las colonias; o bien Fétiches européens, como una instalación formada por tres pequeñas estatuas de mujeres negras, que en su vestimenta, acciones o postura corporal, ostentan distintos efectos de la colonización o sugieren una vulnerabilidad frente a las miradas "exotizantes" sobre sus cuerpos femeninos, son presentados bajo el título homónimo. 
Si consideramos que los surrealistas fueron afectados por un conjunto de ideas sobre el primitivismo -afectos que produjeron efectos estéticos, existenciales y políticos-, podemos pensar en una especie de afectación de segundo orden por parte de los creadores de Légitime Défense, que produjo efectos particularmente en sus debates identitarios. Más específicamente, podemos decir que sus autores fueron afectados por los afectos primitivistas de los surrealistas.

De este modo, los martinicanos pasaron a lo largo de las divergencias entre surrealistas y comunistas apropiándose y siendo afectados por sus debates centrales de un modo particular y creativo. Los efectos de estas afectaciones y, sobre todo, el modo como estos debates conformaron los tópicos centrales del surrealismo martinicano de Légitime Défense, serán analizados a continuación.

\section{La legítima defensa martinicana: surrealismo y anticolonialismo}

Para los autores de Légitime Défense, la idea de primitividad, central para el movimiento surrealista, fue pensada de una manera muy particular: fue asociada al origen africano del pueblo martinicano. Como consecuencia, tomaron para sí la idea positivada de "primitivo", vinculándola a una noción de "mentalidad negra" que "rechaza el poder y acepta la vida", "que tiene un potencial en general más elevado de revuelta y de alegría", como un elemento central y constitutivo de la propia identidad martinicana. Por más que podamos, en una lectura posterior, asociar esta postura a una visión esencializada del "negro"7 -que debe ser comprendida en su momento histórico, anterior y a la vez anticipatorio del propio movimiento de la negritud-, lo que se pretende considerar en este análisis son sus efectos performativos en la producción de una identidad martinicana.

Además, los integrantes de la revista, de modo similar a como los surrealistas "se servían" contextualmente de la literatura, la consideran una "herramienta provisoria": "esta pequeña revista, es una herramienta provisoria; si ella quiebra, sabremos encontrar otros instrumentos" (Léro et al. 1). Del mismo modo, su situación de "antillanos de lengua francesa" en 1932 es vista como parte de condiciones de tiempo y espacio igualmente provisorias, que delimitan - "sin circunscribir"- un campo provisional de acción: "Nosotros aceptamos con indiferencia las condiciones de tiempo y espacio que nos definen en 1932 como Antillanos de lengua francesa, y de este modo delimitan -sin de ninguna forma circunscribir- nuestro primer campo de acción” (1; énfasis mío).

Como podemos observar, las propias reflexiones de los autores parecen surgir como un metacomentario acerca de las posibilidades y efectos de su condición: el

6 Texto de presentación de la revista.

7 El propio René Ménil, uno de los autores de la revista que se convirtió en un crítico literario e intelectual fundamental para las reflexiones sobre identidad martinicana, hizo esta crítica años más tarde, en 1978. 
acceso privilegiado a los debates surrealistas y marxistas no deja de ser un efecto inesperado de la "delimitación" espacio-temporal de su condición de "antillanos de lengua francesa", provenientes de una sociedad colonial y al mismo tiempo situados en París en el momento de efervescencia de estos debates. Así, los usos que hacen del surrealismo y del marxismo -que pueden ser entendidos, de modo similar, como "herramientas provisorias"- dan cuenta de esta "no circunscripción" y surgen como ejemplo de apropiación creativa de su propia condición colonial. Afectados por las premisas surrealistas, se mostraban libres para utilizar incluso las herramientas coloniales, lo que marca una distancia -manifestada en la noción de indiferencia-con la situación colonial a la cual estaban circunstancialmente sometidos.

Es en este sentido que consideramos la doble vinculación de los autores de la revista al movimiento surrealista y al marxismo, anunciada en tono de manifiesto en el texto de presentación de la misma:

Nosotros nos dirigimos acá contra todos aquellos que no se encuentran ahogados
por este mundo capitalista, cristiano, burgués, en el cual en contra de nuestra
voluntad formamos parte. El Partido Comunista (III Internacional) está en
vías de jugar en todos los países la carta decisiva del "Espíritu”. [...] Nosotros
creemos sin reservas en su triunfo y esto porque revindicamos el materialismo
dialéctico de Marx. [...] Sobre el plan concreto de los modos figurados de la
expresión humana, nosotros aceptamos igualmente sin reservas el surrealismo
al cual -en 1932- unimos nuestro devenir (Léro et al. 1).

Cabe señalar que la apropiación del nombre del texto de Breton de 1926 para titular la revista parece ser más bien una declaración de filiación voluntaria al movimiento surrealista, que propiamente una alineación a los términos de la defensa surrealista frente a las ofensivas del Partido Comunista. La "legítima defensa" del grupo martinicano es de otro orden. En primer lugar -y sobre todo-, se trata de una legítima defensa contra el colonialismo, tan "legítima" que están libres para ponerse al margen de las querellas entre surrealistas y comunistas, y utilizar a su modo, y según su necesidad, ambas "herramientas provisorias". La tensión subyacente a una doble adhesión al comunismo y al surrealismo no los alcanza directamente, de modo que, en vez de replicar las tentativas de ajuste y conciliación de los surrealistas franceses, se ponen al margen de un debate que no es suyo y, en una actitud modernista, canibalizan a ambos, incorporándolos y volviéndolos propios.

Con el fin de discutir las formas en las cuales los autores de Légitime Défense fueron afectados por estos debates, así como sus efectos, es necesario analizar cómo concibieron estas relaciones con el surrealismo y con las ideas marxistas. Para ello, vale la pena atender a las principales temáticas abordadas en la revista. 


\section{El debate anticolonialista en Légitime Défense}

Dado que Légitime Défense se inserta en el contexto general de cuestionamiento de los valores de la sociedad europea en el periodo francés de entreguerras, en que se da una "coexistencia y colaboración entre comunistas y surrealistas" (Lewis 9), la crítica al colonialismo realizada por sus autores tiene como principal destinatario a la burguesía martinicana, cuyas marcas de distinción se anclaban en la adopción de valores y gustos de la burguesía francesa, lo que puede ser considerado como uno de los efectos del carácter asimilacionista de la propia política colonial francesa. ${ }^{8} \mathrm{En}$ relación con lo anterior, autores como Tomich destacan los efectos de la política de asimilación francesa sobre la cuestión identitaria en Martinica y, particularmente, sobre la formación de los intelectuales de las Antillas francesas: "El intelectual negro caribeño era estimulado a 'asimilar la cultura francesa', y siendo así, a ascender a la elite negra escolarizada” (355).

En el texto de presentación de Légitime Défense, sus autores critican duramente a la "burguesía de color martinicana" (sic), "una de las cosas más tristes del mundo", declarándose (en tanto hijos de esta burguesía) como "traidores de clase”. Así, la declaración de "traición de clase" poseía un aspecto de confrontación directa con el colonialismo, una vez que apuntaba a la traición del propio modus operandi del sistema colonial francés, que necesitaba de la formación (en la metrópoli) de una burguesía colonial comprometida con sus valores. Cabe señalar que, en el caso de la burguesía martinicana, el debate de clase remetía también a un debate de raza, toda vez que la burguesía estaba compuesta sobre todo por los llamados mulâtres ("mulatos", en la denominación local), en condiciones en que la mayoría de la población pobre y, en la época de creación de la revista, iletrada y hablante del créole, era constituida por los negros descendientes de los antiguos esclavos de las plantaciones, o de los llamados "negros congo" reclutados como trabajadores brazales en las plantaciones en el periodo postabolición. ${ }^{9}$ Así, se trataba de una sociedad altamente estratificada y racializada, compuesta, además, por una pequeña fracción de blancos hacendados (aproximadamente el uno por ciento), herederos de los esclavistas (familias tradicionales definidas como blancs créoles o "blancos criollos", también llamados localmente Békés), que poseía la mayor parte del poder económico y, en la época, social. Esta verdadera casta poseía una dinámica de reproducción interna que conjugaba la mantención de su "especificidad racial" con su posición económica dominante (Beaudoux), a través de estrategias de alianzas matrimoniales en el interior del grupo (o con grupos similares de otras islas, como

8 A este respecto, Pierre Bourdieu analiza las ambigüedades del modelo de imperialismo francés en su texto Dos imperialismos de lo universal (153-8).

9 También se reclutaron indios, que todavía no eran mencionados en los debates identitarios en formación. 
Guadalupe), que combinaban el objetivo de mantención de su posición de elite económica y social con una obsesión por la "preservación de la pureza de la raza". ${ }^{10}$

Relacionado con lo anterior, en "Note touchant la bourgeoisie de couleur française", Jules Monnerot señala la existencia de una "plutocracia blanca hereditaria” en Martinica, la que contribuye aún más a este pacto entre la burguesía local y la metropolitana: en el escenario de inmovilidad social en el cual la gran mayoría de las tierras seguía concentrada en manos de los descendientes de los blancos esclavistas, herederos de las plantaciones de caña de azúcar y de las usinas productoras de ron (cuatro quintos de las tierras de la isla, según el texto), la única forma de ascensión social de los afrodescendientes en Martinica se daría vía acceso a los cargos públicos de la administración colonial, base de la pequeña y mediana burguesía martinicana; la única forma de distinción social, por la adopción de los valores y hábitos franceses. En un retrato ácido del funcionamiento del sistema colonial martinicano postabolición -en el cual "la situación de los cortadores [asalariados] de caña de 1932 no es mejor que aquella de los cortadores de caña de 1832" (3)-, Monnerot declara: "Esta aristocracia rural, como es minoritaria numéricamente, no abastece de representantes al Parlamento. Ella los compra simplemente. Los representantes son elegidos sobre todo entre la burguesía de color y sus ideas políticas desafían en general a un análisis" (4). Además, respecto a los hijos de esta "burguesía de color, criados en el culto del fraude", que realiza sus estudios universitarios en Francia, "ellos se muestran ávidos por conformarse a los modos y caracteres de la mayoría de sus condiscípulos europeos" (4). En este sentido, habla de su deseo de "no hacerse notar" (en tanto negros, subentendido), de "asimilarse" a los franceses. Este "deseo de asimilarse" del que habla el autor sella, finalmente, su acuerdo con el "pacto colonial" y su distanciamiento del pueblo martinicano.

A este respecto, Tomich apunta como uno de los efectos de la política asimilacionista francesa en las elites martinicanas el hecho de que el status de clase media resultante de una educación en Francia terminaba por representar "un obstáculo para la identificación racial y cultural con la masa de la población" (355, cursivas de la autora). Compartiendo el análisis de George Padmore, el autor señala la diferencia entre las elites coloniales británicas -que se tornaron vanguardia en los movimientos nacionalistas- $y$ las elites coloniales francesas, estrechamente comprometidas con el gobierno colonial francés (355). Esta diferencia fundamental, efecto innegable de la política asimilacionista, se revela como algo mucho más allá de una alianza política: se refiere a la percepción identitaria misma de las elites martinicanas, como es analizado

10 Pese a que se esté utilizando el tiempo pasado en este texto, con el fin de ajustarse a los debates realizados por los autores de Légitime Défense en 1932, datos recientes de trabajo de campo realizados por la autora de este artículo (2011-2013) dan cuenta de la permanencia de los Békés en la isla, con su dinámica de matrimonios internos, actualmente expandida para alianzas con otros grupos económicos extranjeros; sin embargo, se mantiene la regla de exclusión de matrimonios interraciales. 
ejemplarmente por Fanon (Peau noire, masques blancs y Pour la révolution africaine $)^{11}$ y anticipado por los creadores de Légitime Défense.

Así, la crítica más general al colonialismo realizada por los surrealistas y comunistas franceses se volcó, en la revista, sobre todo al colonialismo "introyectado" en la burguesía martinicana, anticipando las reflexiones realizadas por Frantz Fanon en su clásico Piel negra, máscaras blancas, de 1952. En relación con lo anterior, en el mismo artículo en que analiza los hábitos de clase de los hijos de la burguesía martinicana, Monnerot plantea que "ellos, a fuerza de un conformismo se hacen un blanqueamiento" (4, énfasis mío). En el mismo sentido, en el artículo "Généralités sur l’écrivain de couleur antillais", René Ménil escribe: “se argumenta que las pequeñas Antillas francesas, a lo largo de los siglos, asimilaron de tal modo las lecciones de la civilización francesa que actualmente los negros antillanos no pueden pensar de otro modo que no sea como los blancos europeos" (7). Para el autor, "no se trata de una hipocresía consciente y maquiavélica, sino de una hipocresía objetiva, inconsciente” (7).

Este aspecto reaparece también en "Misère d'une Poésie", de Étienne Léro: "El antillano, completamente lleno de moral blanca, de cultura blanca, de educación blanca, de prejuicios blancos, estalla en sus plaquetas la imagen inflada de sí mismo. Ser una buena copia del hombre blanco, es lo que lo sustenta como razón social así como razón poética" (10).

En el texto, el debate sobre la identidad martinicana es realizado a partir de la crítica a la imitación de las formas poéticas francesas por los miembros de la burguesía de la época. En su análisis de esta poesía, que clasifica como mediocre, el autor denuncia la inexistencia de una poesía antillana auténtica. Así, el deseo de "mimetizarse" con la burguesía francesa, basado en la negación y/o silencio de sus raíces africanas, se refleja igualmente en una literatura que busca "mimetizarse" con la literatura producida en la metrópoli. Para Léro, esto se vincula directamente con el orden social existente, que forma una burguesía colonial completamente comprometida con los valores de la sociedad francesa. Además, el autor critica la negación de la lengua créole por parte de esta burguesía. En la búsqueda de los agentes capaces de constituir una "auténtica literatura martinicana", influenciados por la agenda comunista, el "proletariado negro" (que podría ser identificado, en este caso, con los trabajadores rurales de las usinas de azúcar) fue visto como el depositario de esta autenticidad. En el texto, podemos observar la influencia marxista no solamente en los términos utilizados para la discusión de temas relacionados con la identidad martinicana, sino en la idea de superación del sistema colonial y capitalista, a partir de un debate mediado por la reflexión sobre la literatura: "El día que el proletariado negro, sorbido en las Antillas por una clase de mulatos parásita vendida a blancos degenerados acceda, rompiendo

11 En su texto de 1954, "Antillais et Africains", Frantz Fanon analiza los efectos de la política asimilacionista francesa en la autopercepción de los martinicanos (como "casi-metropolitanos", o casi-blancos) en el periodo de entreguerras: "Entre todos los Antillanos, antes de la guerra de 1939, no había solamente la certeza de una superioridad en relación al Africano, mas aquella de una diferencia fundamental. El Africano era un negro; el Antillano, un Europeo" (29). 
una doble sujeción, al derecho de comer y a la vida del espíritu, solamente este día existirá la poesía antillana” (12).

Así, queda clara en el texto de Léro la idea de creación tanto de una nueva poética, inseparable de la idea de revolución, como de una "identidad martinicana", inseparable de una idea de cultura negra popular antillana. De esta manera, el arte como instrumento de revolución (existencial y política), tal como fue presentado en los primeros años del surrealismo, reaparece en Légitime Défense introduciendo cuestiones específicas de la sociedad colonial caribeña.

Particularmente en la crítica realizada por el grupo de Légitime Défense a la asimilación de la cultura francesa por la burguesía martinicana, merece ser destacado el uso del concepto de inconsciente en la elaboración de la propia crítica anticolonialista, lo que anticipa el enfoque sociogenético elaborado por Frantz Fanon en su análisis de los efectos del colonialismo en los colonizados (Peau noire, masques blancs). El análisis específico del deseo de "mimetizarse" con el blanco europeo, que incluye el prejuicio, negación y distanciamiento de todo lo que fuese considerado "negro", identificado por los autores de la revista en la burguesía martinicana, será profundizado veinte años después por Fanon, sobre todo en lo concerniente a sus efectos en los sujetos colonizados.

En ese sentido, el propio Ménil definió, en el texto escrito para la reedición de la revista, el proyecto de Légitime Défense como "más fanonista avant la lettre que senghoriano o incluso césairista"12 (s/n.), haciendo referencia a los dos principales exponentes del movimiento de la negritud, el senegalés Léopold Sedar Senghor y el martinicano Aimé Césaire. Así, la revista, que por lo demás es anterior al concepto de negritud, enmarca la discusión racial al interior de las discusiones de clase realizadas por el marxismo. Según Ménil,

mientras la négritude afirma la prioridad de la lucha cultural sobre la lucha política, la prioridad de los "valores negros" sobre las contradicciones sociales- Légitime Défense, al contrario, comprometida sobre todo con la lucha antiimperialista que posiciona a los pueblos colonizados contra las burguesías occidentales y su propia burguesía, sitúa la acción política en el cuadro marxista de las transformaciones sociales y sólo concibe el desarrollo de los "valores negros" en el interior de este combate político (s/n.).

Es desde este marco que podemos comprender, por ejemplo, el debate identitario propuesto por Léro a partir del enfoque marxista. Por otro lado, si la cuestión del inconsciente introducida por el surrealismo es utilizada en la elaboración de la ima-

12 En este análisis, el autor hace referencia al senegalés Léopold Sedar Senghor y al martinicano Aimé Césaire que, juntamente con el guyanés Leon Damas, forman la tríada de poetas creadora del movimiento de la négritude en Francia en los años treinta. Cabe señalar que este no debe ser visto como un movimiento homogéneo, pues existen usos y apropiaciones distintas del término entre sus propios creadores. Para Aimé Césaire, por ejemplo, el concepto de negritud se anclaba en una idea universalista, en tanto que para Léopold Sedar Senghor, la idea de negritud poseía un carácter predominantemente esencialista, vinculado a una idea de emocionalidad africana contrapuesta a una racionalidad occidental. 
gen de "colonialismo introyectado", el uso del concepto tal como es realizado por el movimiento surrealista ofrece una posibilidad de "liberación" a los sujetos coloniales: en último análisis, el "sumergimiento surrealista en el inconsciente" podría ser la vía de acceso a una identidad martinicana aún desconocida.

De este modo, si el deseo inconsciente de imitación de los valores europeos por parte de la burguesía martinicana se hacía sentir en sus formas estéticas, los surrealistas martinicanos pasaron a reivindicar su "no-europeidad" y su "condición de negros", reclamando para sí la noción de primitivismo positivado que ofrecía el surrealismo en su crítica a la racionalidad occidental. Para los intelectuales martinicanos, el surrealismo fue un instrumento particular de liberación, en el cual la propia "fantasía primitivista" (Foster) -que consideraba que "el otro, normalmente supuesto que es de color, tiene acceso especial a procesos psíquicos y sociales primarios que al sujeto blanco le están de alguna manera vedados" (178)- servía como legitimación del proyecto de emergencia de una identidad martinicana libre de las amarras coloniales. Este aspecto es señalado también por Tomich, quien argumenta que, al realizar una inversión del sistema de valores a través de la positivación del primitivo y de la condena de la civilización occidental, el surrealismo se presentó como "un modo de liberación de la mentalidad impuesta por esta" (364).

El surrealismo, en tanto movimiento estético con derivaciones políticas, y el marxismo, en tanto teoría política con implicaciones estéticas, afectaron a los creadores de la revista y modularon un primer tópico discursivo -anticolonialista, anticapitalista, antirracionalismo occidental, de exaltación del no europeo y del "primitivo"- que marca el discurso insurgente de Légitime Défense. Por primera vez, un grupo de intelectuales de una colonia francesa se apropiaba de discursividades surgidas en la "metrópoli" para una crítica al colonialismo "desde adentro", a partir de la voz de sus habitantes. Además, podemos decir que estos movimientos formaron sensibilidades estéticas y políticas que están en la base de los debates identitarios llevados a cabo por los movimientos literarios posteriores, comenzando por el movimiento de la negritud y que se profundizarán, diez años después, en la revista literaria Tropiques (1941-1945), ideada por Aimé Césaire, Suzanne Césaire y uno de los integrantes del grupo de Légitime Défense, René Ménil.

Aunque haya sido producida en el contexto colonial, Légitime Défense inaugura una relación entre movimientos literarios y producción de identidades en la Martinica que continuó produciendo sus efectos en el periodo postcolonial, como lo demuestran los movimientos literarios postnegritud, tales como los debates decoloniales presentes en la antillanité de Édouard Glissant y los planteamientos identitarios de la créolité de Bernabé, Chamoiseau y Confiant. De este modo, cuestiones inicialmente colocadas por las vanguardias martinicanas, empezando por Légitime Défense, se reconfigurará $\mathrm{n}$ a través de estas corrientes literarias que, sumadas a la situación de semicolonialidad aún existente en la sociedad martinicana, demuestran que los debates introducidos por esta vanguardia todavía no están agotados. 


\section{Referencias}

Barthes, Roland. Mitologias. Río de Janeiro, Bertrand Brasil, 2001.

Beaudoux, Edith Kovats. Les blancs créoles de la Martinique. París, L'Harmattan, 2003.

Bernabé, Jean, Patrick Chamoiseau y Raphaël Confiant. Éloge de la créolité. Paris, Gallimard, 1993.

Blachère, Jean-Claude. "La pensée anticolonialiste d'André Breton”. Mélusine, n XVI (1997), pp. 29-46.

Bonfiglio, Florencia. "Aimé Césaire y Tropiques: comienzos literarios en el Caribe francés”. Literatura y Lingüística, n 25 (2007), pp. 17-37.

Bourdieu, Pierre. "Dos imperialismos de lo universal". Intelectuales, política y poder. Buenos Aires, Editorial Universitaria de Buenos Aires, 1999.

Bouvier, Pierre. Aimé Césaire, Frantz Fanon: portraits de décolonisés. París, Les Belles Lettres, 2010.

Breton, André. "Légitime défense". La Révolution Surréaliste (1924-1929). Collection Complète. Paris: Jean-Michel Place, 1975 [1926].

---. Manifestes du surréalisme. Paris: Gallimard, 2008.

Breton, André et al. La Révolution Surréaliste (1924-1929). Collection Complète. Paris Jean-Michel Place, 1975.

Césaire, Aimé. Discours sur le colonialisme. Paris/Dakar, Présence Africaine, 2004 [1955].

---. Le discours sur la négritude. Fort-de-France, Berger Bellepage, 2007 [1987].

Césaire, Aimé et al. Tropiques. 1941-1945. Collection Complète. Paris : Jean-Michel Place, 1994 [1978].

Clifford, James. The Predicament of Culture: Twentieth-Century Ethnography, Literature and Art. Cambridge/Massachusetts/London, Harvard University Press, 1988.

Cole, Lori. "Légitime défense: From Communism and Surrealism to Caribbean SelfDefinition". Journal of Surrealism and the Americas, vol. 4, n' 1 (2010), pp. 15-30.

Dash, J. Michael. "Le Je de l'autre: Surrealist Ethnographers and the Francophone Caribbean”. L'esprit Créateur, vol. 47, n 1 (2007), pp. 84-95.

Davis, Gregson. Aimé Césaire. Cambridge/, New York, Cambridge University Press, 1997. De L'Estoile, Benoît. Le gout des autres: de l'exposition coloniale aux arts premiers. Paris: Flammarion, 2007.

Fanon, Frantz. Peau noire, masques blancs. Paris, Seuil, 1971 [1952].

---. “Antillais et africains”. Pour la révolution africaine. Paris, La Découverte, 2006 [1954]. Fonkoua, Romuald. Aimé Césaire. Paris, Perrin, 2010.

Foster, Hal. El retorno de lo real: la vanguardia a finales de siglo. Madrid, Akal, 2001. Glissant, Édouard. Le discours antillais. Paris: Gallimard, 1997.

Hobsbawm, Eric. Historia del siglo Xx. Buenos Aires, Crítica, Grijalbo Mondadori, 1998. Kesteloot, Lylian. Césaire et Senghor: Un pont sur l'Atlantique. Paris, Harmattan, 2006. Kesteloot, Lylian y Bartélemy Kotchy. Aimé Césaire, L’homme et l'oeuvre. Paris, Présence Africaine, 1973. 
Lagrou, Elsje. "A arte do Outro no surrealismo e hoje”. Horizontes Antropológicos, vol. $14, \mathrm{n}^{\circ} 29$ (2008), pp. 217-230.

Leclercq, Sophie. "Le colonialisme mis à nu. Quand les surréalistes démythifiaient la France coloniale (1919-1962)”. Revue historique, nº 646 (2008), pp. 315-336.

Leiris, Michel. Contacts de civilisations en Martinique et en Guadeloupe. Paris, unesco-Galimard, 1955.

Léro, Étienne. Misère d’une Poésie, Légitime Défense. Etienne Léro et al. Paris, Jean-Michel Place, 1979 [1932], pp. 10-12. https://gallica.bnf.fr/ark:/12148/bpt6k326310. image Visitado 8 de mar. de 2016.

Léro, Etienne, Thélus Léro, René Ménil, Jules-Marcel Monnerot, Michel Pilotin, Maurice-Sabas Quitman, Auguste Thésée y Pierre Yoyotte. Légitime Défense. Paris, Jean-Michel Place, 1979 [1932]. Web. https://gallica.bnf.fr/ark:/12148/ bpt6k326310.image Visitado 8 de mar. de 2016.

Lewis, Shirin K. "Légitime défense: A Precursor to Modern Black Francophone Literature". Race, Culture and Identity: Francophone West African and Caribbean Literature from Négritude to Créolité. Lanham, MD, Rowman and Littlefield, 2006.

Ménil, René. "Généralités sur lécrivain de couleur antillais”. Légitime Défense. Léro, Etienne et al. París, Jean-Michel Place, 1979 [1932], pp. 7-9. https://gallica.bnf. fr/ark:/12148/bpt6k326310.image Visitado 8 de mar. de 2016.

---. "Légitime défense”. [Prólogo a la reedición de 1979]. Légitime Défense. París, JeanMichel Place, 1979 [1932], s. n. https://gallica.bnf.fr/ark:/12148/bpt6k326310. image Visitado 8 de mar. de 2016.

Monnerot, Jules. "Note touchant la bourgeoisie de couleur française", Légitime Défense. Etienne Léro et al. París, Jean-Michel Place, 1979 [1932], pp. 3-4. https://gallica. bnf.fr/ark:/12148/bpt6k326310.image Visitado 8 de mar. de 2016.

Padmore, George. Pan-Africanism or Communism. New York, Doubleday, 1971.

Palermo, Lynn E. “L'Exposition Anticoloniale: Political or Aesthetic Protest?”. French Cultural Studies, vol. 20, nº 1 (2009), pp. 27-46.

Reynaud-Paligot, Carole. "Les surréalistes et la guerre d’Algérie". French Cultural Studies, $\mathrm{n}^{\circ} 13$ (2002), pp. 33-47.

Richardson, Michael. "An Encounter of Wise Men and Cyclops Women: Considerations of debates on surrealism and anthropology". Critique of Anthropology, vol. 13, nº 1 (1993), pp. 57-75.

---. Refusal of the Shadow: Surrealism and the Caribbean. London-New York, Verso, 1996.

Rosemont, Franklin y Robin Kelley. Black. Brown \& Beige. Surrealist Writings from Africa and the Diaspora. Austin, University of Texas Press, 2010.

Stocking, George. "The ethnographic sensibility of the 1920s and the dualism of the anthropological tradition”. Romantic Motives: Essays on Anthropological Sensibility. Org. George Stocking. Madison, Wisconsin, The University of Wisconsin Press, 1989, pp. 208-279. 
Tomich, Dale. "The Dialectic of Colonialism and Culture: The Origins of the Negritude of Aimé Césaire". Review Fernand Braudel Center, vol. 2, nº (1979), pp. 351-385. Toumson, Roger y Simonne Henry-Valmore. Aimé Césaire: le nègre inconsolé. Paris: Vents d’ailleurs, 2008.

Enviado: 9 julio 2017 Aceptado: 16 abril 2018 